NBER WORKING PAPER SERIES

THE IMPACT OF ANNUITY INSURANCE

ON SAVINGS AND INEQUALITY

,

Laurence J. Kotlikoff

John Shoven

Avia Spivak

Working Paper No. 1403

NATIONAL BUREAU OF ECONOMIC RESEARCH

1050 Massachusetts Avenue

Cambridge, MA 02138

July 1984

We thank Zvi Eckstein, Bronwyn Hall, Joe Stiglitz, Truman Bewley, Ludo Van der Heyden, Linus Yamane, and Steven Galatis for very helpful discussions. Steven Galatis and Linus Yamane provided excellent research assistance. The research reported here is part of the NBER's research programs in Pensions and Taxation and project in Government Budget. Any opinions expressed are those of the authors and not those of the National Bureau of Economic Research. 


\section{The Impact of Annuity Insurance \\ on Savings and Inequality}

\section{$\underline{\text { ABSTRACT }}$}

This paper examines the amount of precautionary savings arising from life span uncertainty by comparing saving behavior under perfect insurance arrangements with that arising under imperfect arrangments, namely when longevity risk can be pooled only with members of one's own family. We consider both intergenerationally altruistic preferences and selfish (zero bequest motive) life cycle preferences, determining stochastic steady state wealth levels and wealth distributions in both models.

The central findings of the paper are: (1) perfecting insurance arrangements can sharply lower savings in both intergenerationally altruistic and life cycle economies and (2) in intergenerationally altruistic economies perfecting annuity insurance can greatly influence the degree of inequality; indeed, in the long run in our model, where everyone has the same endowments, switching from imperfect family insurance to perfect insurance can mean the difference between absolute inequality and absolute equality.

Laurence J. Kotlikoff

Boston University 725 Commonwealth Avenue Boston, MA 02215
John Shoven

Department of Economics Stanford University Encina Hall, 4 th Floor Stanford, CA 94305

Avia Spivak

Department of Economics University of Pennsylvania 3718 Locust Walk/CR

Philadelphia, PA 19104 


\title{
The Impact of Annuity Insurance \\ on Savings and Inequality
}

\author{
Laurence J. Kotlikoff \\ John Shoven \\ Avia Spivak
}

While death and taxes may be the two most certain elements in one's life, the date of one's death is surely one of the least certain. Uncertainty concerning the length of life is obviously of great importance to saving decisions; "taking it with you" is not an option, but immediately consuming all resources (less an intended bequest) is no alternative either, since with high probability one will still be alive, but be very poor, in the immediate future. To avoid the prospect of remaining alive in a state of relative poverty, risk averse individuals will be cautious about their rate of consumption. The extent of precautionary saving motivated by life span uncertainty depends on the availability of market and non-market annuity insurance. Annuity insurance permits those who live longer than average to share the economic risks of this outcome with those who live shorter than average. This paper examines the amount of precautionary savings arising from life span uncertainty by comparing saving behavior under perfect insurance arrangements with that arising under imperfect arrangments, namely when longevity risk can be pooled only with members of one's own family. We consider both intergenerationally altruistic preferences and selfish (zero bequest motive) life cycle preferences, determining stochastic steady state wealth levels and wealth distributions in both models. 1 
The central findings of the paper are: (1) perfecting insurance arrangements can sharply lower savings in both intergenerationally altruistic and life cycle economies and (2) in intergenerationally altruistic economies perfecting annuity insurance can greatly influence the degree of inequality; indeed, in the long run in our model, where everyone has the same endowments, switching from imperfect family insurance to perfect insurance can mean the difference between absolute inequality and absolute equality.

There are now several studies that examine the impact of annuity insurance on saving. Sheshinski and Weiss (1981) were the first to point out that a fully funded Social Security program could alter household saving through its provision of annuity insurance, assuming such insurance is not otherwise available. Hubbard (1983) reaches a similar conclusion in a partial equilibrium life cycle analysis. Kotlikof and Spivak (1981) and Davies (1981) discuss the size of involuntary bequests in life cycle models in the complete absence of insurance arrangements. Fuller descriptions of life cycle economies in the absence of annuity insurance are presented by Eckstein, Eichenbaum, and Peled (1983) and Abel (1983). Both papers consider the stochastic steady state properties of economies in which agents involuntarily leave bequests to their children.

While each of these papers indicate that improvements in annuity insurance reduces precautionary saving, their specification of bequest behavior in the absence of annuity insurance is either incomplete or rather arbitrary. For example, Eckstein et.al. and Abel assume that while parents are selfish and have no interest in their children, they nonetheless involuntarily 


\section{$-3-$}

bequeath all their wealth to precisely their own children, extracting no quidpro-quo in exchange. An alternative assumption explored by Kotlikoff and Spivak (1981) is that selfish parents and selfish children jointly pool longevity risk in a manner that is mitually beneficial. Kotlikoff and Spivak point out that longevity risks are substantial as measured by the amount of resources even mildly risk averse selfish individuals would sacriflce to gain access to fair annuity insurance. In addition they demonstrate that risk sharing among even as few as two relatives can provide a large fraction of the gains available from perfect insurance. Hence, in selfish life cycle models, longevity risk pooling between parents and children appears well "worth the trouble," with the gains far exceeding any reasonable transactions costs. In contrast to the selfish life cycle model, in the altruistic model, the pooling of otherwise uninsureable longevity risk between parents and children is an immediate implication of utility maximization since the utility of children is an argument in the utility function of parents.

Our model of risk sharing arrangements between parents and children assumes the smallest possible family risk sharing pool, namely, at most one parent sharing risk with one child at any point in time. Since family insurance approaches perfect insurance as the number of family members increases, this assumption leads to the largest precautionary motive for saving and provides an upper bound for calculating the potential decline in savings resulting from perfecting annuity insurance arrangements. 2

$$
\text { While at most two relatives are simultaneously alive, risk sharing }
$$

In both the altruistic and selfish models also involves all future genera- 
tions. In the altruistic model current relatives conciously take into account the impact of their behavior on their decendents' inheritances and, therefore, their levels of expected welfare. As a consequence, altruistic families automatically share any current adverse shocks with future generations by reducing the bequests they leave to future generations. In the life cycle model the risk sharing arrangments between current parents and children is chosen taking into account that today's adverse shocks will affect the future bargaining position of current children when they strike selfish deals with their children. This future bargaining with the next generation is, in turn, contingent on the nature of subsequent future bargaining with the succeeding generation, and on and on .... Hence, the solution to the bargaining problem between living family members takes account of the infinite sequence of bargains struck by family descendents.

The next section considers the impact of annuity insurance in an intertemporal altruistic economy in which families can borrow the present value of their certain future labor earnings. Assymptotically the distribution of resources and consumption in this economy approaches complete inequality with successively fewer families holding all the economy's resources and engaging in all the economy's consumption. Section III considers a presumably more realistic financial setting in which altruistic families cannot borrow against the present value of their infinite stream of future earnings. In contrast to the unconstrained borrowing case in which the altruistic economy's savings is infinitely elastic at a particular interest rate, with borrowing constraints aggregate savings is a continuous increasing function of the interest rate. 
In addition, the reduction in steady state wealth from introducing perfect annuity insurance is considerably larger if there are borrowing constraints in the altruistic economy. The borrowing constraints also lead to a stationary wealth distribution in contrast to the increasingly unequal, asymptotically dezenerate wealth distribution arising in the altruistic economy without borrowing constraints. The fourth section contains our life cycle model of bargaining in which non-altruistic agents consider the infinite sequence of selfish bargaining agreements. The calculations in this section suggest a very sizeable effect of perfecting annuity insurance on long run savings. The models in sections II and IV have four potential periods of life, while section III's model has at most two periods of life. A minimum of four periods is necessary to examine selfish life cycle bargaining. While section III's analysis of liquidity constrained altruistic behavior could be formulated in the four period framework, simplifying to two periods greatly reduces the computational costs of solving the problem. To facilitate comparisons of the predictions of the three models all 1llustrative calculations are besed on a common utility function and parameters in the two period model of section III are calibrated on the basis of the four period models' parameterizations. In the final section, $V$, there is a summary of the paper's findings and suggestions for additional research on issues of precautionary savings.

\section{The Unconstrainted Intergenerationally Altruistic Model}

In this model and that of section IV there are four periods of life. People live with certainty for the first three periods and survive to the fourth with probability $P$. Children are one when their parents are three. Individuals 
are exogenously endowed with labor earnings which they receive during the first three periods of life. Hence, the present value of earnings for an altruistic family is certain, and we assume in this section that families can borrow the present value of the infinite stream of earnings.

The family's utility function is taken as separable in consumption of the parent $\left(\mathrm{C}_{\mathrm{f}}\right)$ and the child $\left(\mathrm{C}_{\mathrm{s}}\right)$ over time. Throughout the paper we consider the isoelastic form for utility of consumption at a point in time, $U(C)$, i.e.,

$$
U(c)=\frac{c^{1-\gamma}}{1-\gamma}
$$

where $\gamma$ is the coefficient of relative risk aversion. The utility of children is assumed to enter the family's expected utility function, with weight $\theta$, and future utility is assumed to be discounted by the time preference factor $\alpha$. Let $W_{t}$ stand for the family's total human plus non-human wealth at time $t$. The expected utility of a family with a one period old child and a three period old parent at time $t$ is a function of $w_{t}$ and is denoted, $v\left(w_{t}\right)$. Equation (2) expresses $V\left(w_{t}\right)$ in terms of the certain utility of the child's and parent's immediate consumption, the expected utility of their subsequent period consumption, and the expected utility of the family when the next child is born. For notational convenience the time subscript, $t$, is omitted wherever the time period is implicitly clear. In addition, we set $t=1$ initially.

(2) $\quad V\left(W_{1}\right)=\max \left[\frac{C_{f 3}^{1-\gamma}}{1-\gamma}+\theta \frac{C_{s 1}^{1-\gamma}}{1-\gamma}+\alpha P\left[\frac{C_{f 4}^{1-\gamma}}{1-\gamma}+\theta \frac{C_{S 2, a}^{1-\gamma}}{1-\gamma}+\alpha V\left(W_{3, a}\right)\right]\right.$ 


$$
\begin{gathered}
-7- \\
\left.+\alpha(1-P)\left[\theta \frac{C_{s 2, d}^{1-\gamma}}{1-\gamma}+\alpha V\left(w_{3, d}\right)\right]\right\rfloor
\end{gathered}
$$

The first two terms on the right hand side of (2) are, respectively, the family's utility from the parent's third and the child's first period consumption. The bracketed terms multiplied by aP indicate the family's expected utility in the case the parent lives through the fourth period. The child's second period consumption in this case is $C_{s 2, a}$ and the family's full wealth at the time the initial child is a parent is $W_{3, a^{*}}$ In the case the parent dies early, the child's second period consumption and the family's resources when the child becomes a parent are, respectively, $c_{s 2, d}$ and $w_{3, d}$. The bracketed terms maltiplied by $a(1-P)$ express the family's expected utility if the parent dies early.

The family is constrained in maximizing (2) by:

$$
\begin{aligned}
& W_{1}=C_{f 3}+C_{s 1}+R\left(C_{f 4}+C_{s 2, a}+R W_{3, a}\right) \\
& W_{1}=C_{f 3}+C_{s 1}+R\left(C_{s 2, d}+R W_{3, d}\right),
\end{aligned}
$$

where $R$ is one divided by one plus the interest rate. These equations simply relate the ongoing family's full future resources at the time the child becomes a parent $\left(W_{3, a}\right.$ or $\left.W_{3, d}\right)$ to the appropriately discounted difference between initial family resources and total family consumption during the child's first and second periods. The two constraints correspond to the two possible outcomes -- the parent dying early and the parent dying late.

$$
\text { Given the functional form for } V \text { maximization of (2) subject to (3) }
$$

is straightforward. Consider the following as a possible solution function $V(W)$ : $V(W)=k \frac{W^{1-\gamma}}{1-\gamma}$, where $k$ is a constant. Next replace in $(2) v\left(w_{3, a}\right)$ by $k \frac{1, a}{1-\gamma}$ 
and $\mathrm{V}\left(\mathrm{w}_{3, \mathrm{~d}}\right)$ by $\mathrm{k} \frac{\mathrm{W}_{3, \mathrm{~d}}}{1-\gamma}$. With this substitution $\mathrm{V}\left(\mathrm{w}_{1}\right)$ is now a homothetic function of each of the consumption demands plus $w_{3, a}$ and $w_{3, d}$. Hence, the solution values for the consumption demands and $w_{3, a}$ and $w_{3, d}$ are all proportional to $w_{1}$. Inserting these solutions into (2) and collecting constants, we have:

$$
V\left(w_{1}\right)=k \frac{W_{1}^{1-\gamma}}{1-\gamma}=g(P, \alpha, \theta, R, \gamma, k) \frac{w_{1}^{1-\gamma}}{1-\gamma}
$$

where $g(P, \alpha, \theta, R, \gamma, k)$ is the sum of constants multiplying $\frac{w_{1}^{1-\gamma}}{1-\gamma}$ after solution values have been substituted into (2). From ( 4$), k=g(P, \alpha, \theta, R, \gamma, k)$, and this expression can be used to solve for $k .{ }^{3}$ Hence, we have a proof by construction that $V(W)=k \frac{W^{1-\gamma}}{1-\gamma}$ is the form of the value function in (2).

The homotheticity of the value function (2) permits an immediate characterization of the evolution of full resources for each family through time and for the aggregate economy. The solution to (2) implies:

$$
\begin{aligned}
& \mathrm{w}_{3, \mathrm{a}}=A \mathrm{~W}_{1}, \text { and } \\
& \mathrm{w}_{3, \mathrm{~d}}=\mathrm{DW_{1 } ,}
\end{aligned}
$$

where $A$ and $D$ are constants depending on the model's parameters $P, \alpha, \theta, R$, and $\gamma$. For each family expected resources when the current child becomes a parent, $\mathrm{EW}_{3}$, are related to initial resources by:

$$
E W_{3}=[P A+(1-P) D] W_{1} .
$$

Since this equation holds for all families regardless of their initial value of $\mathrm{W}_{1}$, per capita wealth in the economy will remain constant (assuming an arbitrary large number of families) if and only if: 


$$
P A+(1-P) D=1
$$

Now $A$ and $D$ depend on the interest factor $R$, as well as the fixed survival probability and the fixed preference parameters. Hence, in general equilibrium $R$ mast adjust until the values of $A$ and $D$ satisfy ( 7 ). Since $A$ and $D$ are monotonically increasing functions of $R$, there is a unique value of $R$ that satisfies (7).4 The economy's long run supply of savings is clearly infinitely elastic at this value of $R$, since for larger or smaller values of $R$ full resources (human plus non-human wealth) in the econony either grow indefinitely or decline to zero.

The term $A$ is less than $D$ reflecting the additional demand for fourth period parental consumption in the case the parent lives to consume $\mathrm{C}_{\mathrm{f}^{\circ}}$. Since, by $(7)$, the weighted sum of $A$ and $D$ equals unity, we have $A<1$, and $D$ $>1$. Hence, when expected future resources equal current resources each favorable mortality outcome reduces the family's resources, while each unfavorable mortality outcome increases its resources.

The process governing the family's accumulation and decumilation of wealth through time, with time measured in generations, can be expressed as:

$$
w_{t+1}=w_{t} e^{\varepsilon} t
$$

where $\varepsilon_{t}$ equals $\log A$ with probability $P$ and $\log D$ with probability 1-P. Expressing the process in terms of the logarithm of family resources, we have:

$$
\log w_{t+1}=\log w_{t}+\varepsilon_{t}
$$

The expected value of $\varepsilon_{t}$ is negative since: 


$$
E \varepsilon_{t}=P \log A+(1-P) \log D<\log (P A+(1-P) D)=0
$$

using the concavity of the logrithmic function and (7). Hence, the logarithm of family resources is a random walk with a negative drift. Since each family's resources follows this process, and, by assumption, all families start out with the same initial resources, the distribution of each family's resources as well as the distribution of any functions of family resources, such as the logarithm, are equivalent to the economy wide distributions. The fact that the logarithm of resources follows a random walk with drift indicates that there is no stationary distribution of resources in the economy. Although the mean value of family resources is constant, the distribution of family resources becomes increasingly unequal through time.

To see this rewrite $\varepsilon_{t}$ as $\varepsilon_{t}=-\rho+\mu_{t}$, where $\mu_{t}$ is $1.1 . d$. with zero mean and variance $\sigma^{2}$. The expected logarithm of resources at $t+\tau$ is given by:

$$
E \log W_{t+\tau}=\log W_{t}-\tau p \text {, and }
$$

the variance of the logarithm of resources at $t+\tau$ given $\log w_{t}$ is:

$$
\operatorname{Var}\left(\log W_{t+\tau}\right)=\tau \sigma^{2}
$$

Equations (11) and (12) indicate that for each successive generation the distribution of the logarithm of resources has a smaller mean and a larger variance. Not only are successive resource distributions less equal, as indicated by the Increasing variance of the logarithm, but they are also increasingly skewed. This is suggested by the fact that the mean of the logarithm of resources falls 
through time at a faster rate than its standard deviation rises. Using Chebyshev's inequality one can show that the fraction of families whose resources in the future exceed their current values is bounded by a number that declines with each successive generation. 5 Assymptotically the economy's resource distribution approaches complete inequality with an infintesimal fraction of families holding all the economy's resources and the rest holding no resources. This increasing inequality should be contrasted with the complete equality that arises in the case of perfect insurance under the same assumption that all families have identical initial resources. While each family conciously plans to pursue a policy that leads to immiseration with essentially 100 percent probability, the process of immiseration can be quite slow.

Table 1 presents calculations of the economy's reduction in savings per worker from switching to perfect insurance for a set of illustrative parameter values. Given knowledge of the equilibrium interest rate under imperfect annuity insurance determined in (7), savings per worker is calculated assuming a Cobb-Douglas production function with a capital share equal to .3; $1 . e$. , the economy's general equilibrium condition is that the marginal product of capital equals the interest rate, which provides an equation for computing the economy's stock of savings (capital) per worker. Under perfect insurance the family's budget constraint is simply that the present expected value of consumption equals the present value of resources. As is well known, in this case $R$ equals $\alpha$ in the steady state, and this equation plus the marginal productivity condition are used to solve for steady state savings per worker under perfect insurance. 6 
Table I

The Unconstrained Altruistic Model -

Percentage Savings Reduction from Switching from

Family Insurance to Perfect Insurance

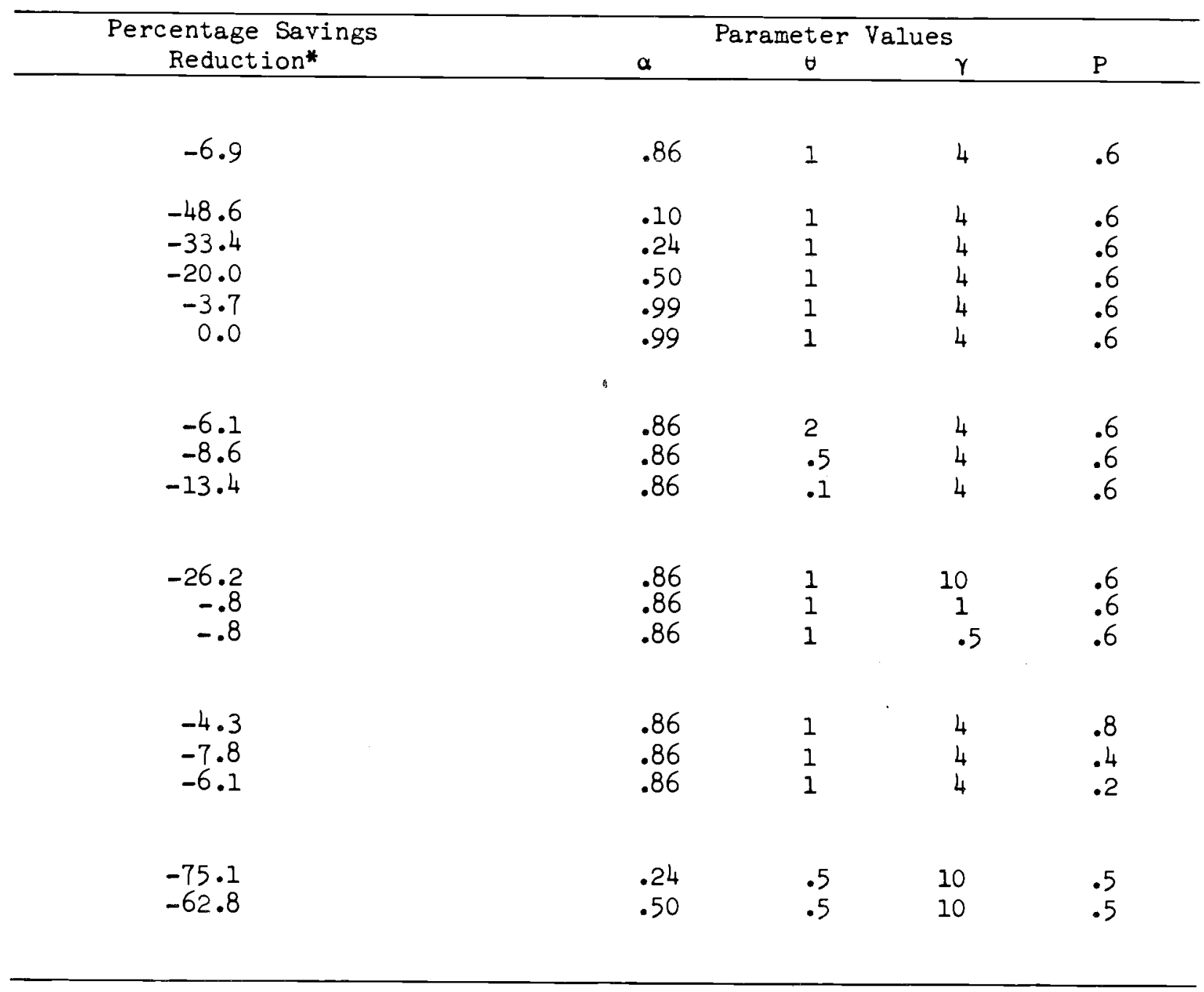

* Calculations assume a Cobb-Douglas production function with capital's output share equal to 30 percent. 
In the base case $\alpha$, the time preference factor equals .86 and $P$, the fourth period survival probability equals .6. If we think of each period as corresponding to roughly 15 years, then the .86 value corresponds to a 1 percent annual time preference rate, and the .6 fourth period survival probability is roughly equivalent to a life span of 54 years. We view "children" in the model as really young adults who are initially roughly age 20 and who are parents of adult children at roughly age 50. Hence, the 54 year life span corresponds to a real world adult life span starting at 20 and ending, on average, at 74 . Base case values of $\gamma$ and $\theta$ are 4 and 1 respectively. Adopting the base case parameters, the altruistic economy's total savings is 7 percent larger with imperfect family annuity insurance than with perfect annuity insurance. This figure is quite sensitive to the time preference rate. Ceteris paribus, lowering $\alpha$ to .5 , which corresponds to a 4.1 percent annual time preference rate, implies a much smaller stock of savings, but a 20 percent difference between savings under family and perfect annuity insurance. For $\alpha$ equals .24 , equivalent to a 10 percent annual time preference rate, there is a 33 percent savings reduction. The reduction is 49 percent for $\alpha$ equals .10. Alternatively, assuming a equals .99 , there is essentially no difference between savings under family and perfect insurance arrangements.7

The sensitivity of savings changes to the weight on the child's utility, $\theta$, is surprisingly small. As $\theta$ rises more weight is placed on the consumption of the child, and, in the limit, as $\theta$ approaches infinity, lifespan uncertainty does not affect utility since families only care about their 
childrens' consumption which is not subject to lifespan risk. Hence as $\theta$ rises $R$ approaches $\alpha$ and the savings reduction from perfect insurance goes to zero. While Table $I$ indicates larger precautionary savings the smaller the value of $\theta$, lowering the value of $\theta$ from 1 to .5 raises precautionary savings by less than two percent. The precautionary savings response to larger values of $\gamma$, the relative risk aversion coefficient, also has the expected positive sign. The magnitude of the savings difference is quite sensitive to $\gamma$. For values of $Y$ below 1 precautionary savings is less than .5 percent of the total; on the other hand, it is 26 percent for $\gamma$ equals 10 , assuming base case values of other parameters. Finally, precautionary savings appears to be maximized for values of $P$ between .4 and .6 . This is also intuitive, since uncertainty disappears from the model when $P$ equals zero or unity. The bottom two rows of table I consider combinations of parameters choosen to raise the level of precautionary savings. For $\alpha$ equals $.24, \gamma$ equals 10 , and $\theta$ and $P$ both equal to .5 there is a 75 percent reduction in the economy's wealth stock associated with switching from family to perfect annuity insurance. This figure declines only slightly, to 63 percent, if a equals .5 and the other parameters take these specified values.

Table II illustrates the transmission of inequality through time. The first generation of families is assumed to have identical resources. The table reports the fraction of resources held by the poorest 10 percent, 30 percent, 50 percent, and 90 percent of families. Since the model's two periods between generations correspond to roughly 30 years, the resource distribution after 10 generations corresponds in real time to roughly 300 years. In the base 
Table II

Resource Inequality in the Unconstrained Altruistic Model after Successive Generations

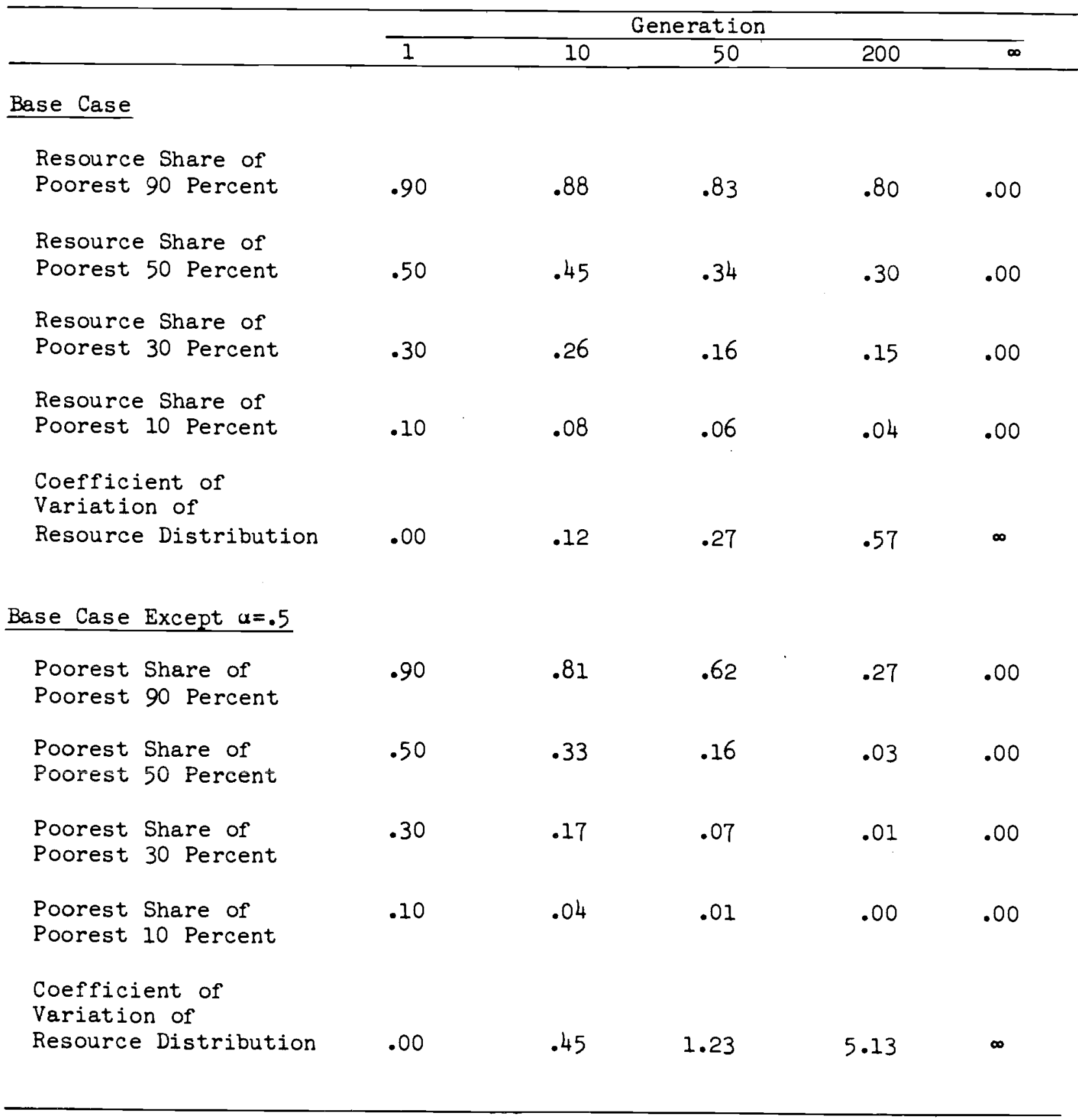


case the increase through time in inequality is extremely slow, with the richest 10 percent holding only 20 percent of total resources after 200 generations. The time preference factor, $\alpha$, appears to be the most critical parameter for affecting the rate at which inequality increases through time. The transition to complete inequality is mach faster if $\alpha$ equals .5 and the other parameters are held at their base case values. Lowering $\alpha$ to .5 produces roughly the same degree of inequality within 10 generations that arises after 200 generations when $\alpha$ equals .86 . After 200 generations $(6,000$ years In real time) of the $\alpha$ equals .5 process, the 10 percent richest families own almost three quarters of all resouces. If a equals .24 (a roughly 10 percent annual time preference rate) the 10 percent richest families own close to 30 percent of all resources after 10 generations. This compares with 19 percent for $\alpha$ equals .5 and 12 percent for $\alpha$ equals .86. A time preference rate of 10 percent per annual is quite high, but is within the range estimated empirically (Hausman (1979)). In addition the associated equilibrium interest rate of 8.5 percent computed on a yearly basis, while high, is not implausible. While risk premiums in uncertainty models are not invariant to the specified number of periods, it may be of some interest to know the welfare gain from perfect insurance in this model. Assuming base line parameter values the lack of perfect insurance has a small -- less than 1 percent -welfare cost as measured by the percentage increase in resources with family insurance required to obtain the expected utility level under perfect Insurance. As expected this figure is highly sensitive to the degree of risk aversion. Ceteris paribus, raising $\gamma$ to 10 raises the equivalent variation to 
almost 16 percent.

To summarize these findings, in the unconstrained intergenerationally altruistic model switching from family to perfect insurance reduces aggregate savings by either a modest or a significant amount depending, primarily, on the time preference rate and degree of risk aversion. The time preference rate is critical for determining the rate at which the resource distribution becomes more unequal. If one accepts a relatively high time preference rate, the model suggests an important potential contribution of Imperfect annuity arrangments in increasing inequality. 


\section{The Constrained Altruistic Model}

The solution to the unconstrained altruistic model involves, in the long run, essentially all families holding close to zero future resources, meaning they are in debt by an amount equal to the present value of their certain future labor earnings. In constrast, this section examines the behavior of the altruistic economy under the assumption that families cannot borrow against their future earnings. For this problem the state variable corresponding to equation (2) is no longer full future resources, rather it is current non human wealth, $A_{t}$. To simplify the numerical calculations required to solve this problem we considered a two period version of the section II model. Each child lives for one period with certainty and survives with probability $P$ for two periods. Hence, when children are born their parents may be dead. The family's expected utility in the case the parent is alive, EU $a$ ' is given by:

$$
\operatorname{EU}_{a}\left(A_{1}\right)=\frac{C_{f 2}^{1-\gamma}}{1-\gamma}+\theta \frac{C_{81, Q}^{1-\gamma}}{1-\gamma}+\alpha V\left(A_{2, Q}\right),
$$

where $A_{1}$ is the family's initial non human wealth. $A_{2, a}$ is the value of such assets at the time the grandchild is born given that the grandfather lives for two periods. If the parent is dead when the child is born the family's expected utility, $\mathrm{EU}_{d}$, is:

$$
E_{d}\left(A_{1}\right)=\theta \frac{C_{81, d}^{1-\gamma}}{1-\gamma}+\alpha V\left(A_{2, d}\right)
$$

where $A_{2, d}$ is the family's assets when the grandchild is born, given that the grandfather dies at the end of period 1. 
The expected utility function $V(A)$ is defined by:

$$
V(A)=P E_{a}(W)+(1-P) E_{d}(A)
$$

If the initial father (the second child's grandfather) is alive, the family maximizes (13) subject to:

$$
\begin{aligned}
& A_{2,8}=\left(A_{1}-C_{f 2}-C_{s 1,8}\right) / R+e, \text { and } \\
& C_{f 2}+C_{s 1, a}<A_{1}
\end{aligned}
$$

In (16) e is the child's first period earnings. The constraint that $\mathrm{C}_{\mathrm{f} 2}+\mathrm{C}_{\mathrm{sl}, \mathrm{a}}$ not exceed $A_{1}$ implies that family assets are never smaller than $e$. The corresponding constraint in maximizing (14) is:

$$
\begin{aligned}
& A_{2, d}=\left(A_{1}-C_{s l, d}\right) / R+e, \text { and } \\
& C_{s 1, d}<A_{1}
\end{aligned}
$$

The value function $V(A)$ as well as the consumption demands $C_{f 2}, C_{s 1, \theta}$, and $C_{s 1, d}$ were computed numerically using the contraction properties of the maximization problem (Denardo (1967)). Specifically, we started with a guess of the function $V(A)$ and used this function to solve for $\mathrm{EU}_{a}\left(A_{1}\right)$ and $E U_{d}\left(A_{1}\right)$. From (15) these $E U_{a}\left(A_{1}\right)$ and $E U_{d}\left(A_{1}\right)$ functions provide a new guess of the $V(A)$ function. This iteration was repeated until the $V(A)$ function converged to its fixed point solution.

While there is a critical interest rate above which the economy's wealth increases without bound, there is a unique distribution of family assets for each interest rate below this critical value. Corresponding to each of these stochastic steady state asset distributions is an agregate stock of assets. Hence, the introduction of liquidity constraints in the 
altruistic model produces (1) a supply schedule of aggregate savings that increases with the interest rate and (2) a non-degenerate wealth distribution. The equilibrium interest rate in this model is no longer determined solely by household preferences, rather it is determined by equating the household supply of savings to firm's demands for savings (capital).

Assuming a Cobb-Douglas production function with a capital share of .3 , a time preference factor $\alpha$ of .742 (corresponding to a 1 percent annual time preference rate), and values of $\theta$ and $\gamma$ equal to 1 and 4 , respectively, the constrained economy's equilibrium steady state capital output ratio is roughly 30 percent larger then in the corresponding unconstrained model. For these parameter values the reduction in aggregate savings from switching to perfect insurance is 50 percent. This number should be contrasted with the 7 percent figure in the first row of Table $I$. The percentage reduction in wealth in this model is highly sensitive to the value of a. At a equals .25 (a 4.7 percent annual time preference rate) the percentage reduction is 95 percent. At a equals .057 (a 10 percent assumed time preference rate) the percentage reduction is 99 percent. The per capita wealth stock is much more sensitive to $\alpha$ in the unconstrained perfect insurance version of this model than in the constrained family insurance version. This is expected since for values of a above a critical level the family is always constrained, and assets in each family equal e, their lower bound (see (16) and (17)). The lower bound on a family's non-human wealth also means a lower equilibrium interest rate than with no borrowing constaints. Since families always save at least as mach with liquidity constraints as they do without 
these constaints, an interest rate equal to or greater than the unconstrained equilibrium value would imply explosive wealth accumlation in the constained case. The lower equilibrium value of the interest rate in the constained model reduces the savings incentives of all agents in the economy, particularly those with the greatest wealth, and, therefore, reduces the dispersion in the distribution of wealth. For the base line parameter values the richest 10 percent of families hold less than 15 percent of economy-wide resources. Inequality in wealth, while limited in all our constained economy calculations, declines rapidly with increases in $\alpha$. 
IV. The Selfish Life Cycle Model

The family insurance model where each member acts solely out of self interest is more complicated. In this case all transfers that occur are the result of ex-ante selfish bargains. A four perlod framework is required here to permit these intergenerational risk sharing arrangements. When the bargaining takes place the child is age one and the parent is age three. The parent has one more period of certain life followed by one period of uncertain life. The agreement reached by parent and child can be thought of as the parent buying an annuity from the child. In return for some money in period 3 the child promises to offer a specified level of support for the parent in period 4 in the event that the parent lives that long. Equivalently, the deal can be arranged such that the child gives the parent some money before period 3 in return for being made beneficiary of the will of the parent. The timing and labelling of payments in these arrangements is not critical; what is critical is that the child share the risk of the parent's lifespan. Both of these arrangements involve such risk sharing. If the parent dies prior to period 4 the child ends up receiving in present value more money than he (she) pays. Alternatively, if the parent dies late the child pays more money in present value than he (she) receives. There is also no requirement that those risk pooling arrangements be explicitly stated or written down. Kotlikoff and Spivak (1981) describes mechanisms for enforcing implicit family annuity contracts.

Both the parent and the child can be mede better off by striking a bargain. However, there is an indeterminacy as to how the gains from trade should be divided. One can imagine an arrangement under which the parent's 
utility in the bargain is just the same as if no deal had been struck, and, therefore, all of the gains from trade go to the child. Alternatively, one can arrange the risk sharing such that all the gains from trade go to the parent. An additional complication is that the child, in striking an arrangement with the parent, considers the 3 rd period bargain he (she) will make with his own child. The expected utility from that future bargain is denoted $\hat{v}$ and depends on the child's level of third period vealth (human plus non-human) $w_{s 3}, i . e ., \hat{v}=\hat{v}\left(w_{s 3}\right)$. Since we assume that successive children all earn identical amounts with certainty in the first three periods of their lives, the resources of the grandchild, with whom the child will bargain, is supressed as an argument of $\hat{v}$.

The frontier of the utility possibilities space with intergenerational bargaining is located by solving

Maximize:

$$
\begin{aligned}
& \frac{c_{f 3}^{1-\gamma}}{1-\gamma}+\frac{\alpha P C_{f 4}^{1-\gamma}}{1-\gamma}+\frac{\theta C_{s 1}^{1-\gamma}}{1-\gamma} \\
& +\theta P\left(\frac{\alpha C_{s 2, a}^{1-\gamma}}{1-\gamma}+\alpha^{2} v\left(w_{s 3, a}\right)\right) \\
& +\theta(1-P)\left(\frac{\alpha C_{s 2, d}^{1-\gamma}}{1-\gamma}+\alpha^{2} v\left(w_{s 3, d}\right)\right)
\end{aligned}
$$

subject to

$$
C_{f 3}+C_{81}+R\left(C_{f 4}+C_{82, a}\right)+R^{2} W_{s 3, a}=W_{s 1}+W_{f 3}
$$

and 
(20)

$$
C_{f 3}+C_{s 1}+R C_{s 2, d}+R^{2} W_{s 3, d}=W_{s 1}+W_{f 3}
$$

As in (2), $C_{f 3}$ and $C_{f 4}$ are the parent's certain and contingent consumption levels in periods 3 and 4 , respectively; $C_{s l}$ is the child's first period consumption, and $C_{s 2, a}$ and $C_{s 2, d}$ are the child's respective second period consumption levels contingent upon the parent being alive or dead in period 4. Children initially have no non-human assets. Each child's certain present value of labor earnings is $W_{s l}$, and his (her) parent's third period human plus non-human wealth is $\mathrm{W}_{\mathrm{f3}}$. Finally, $\mathrm{W}_{\mathrm{s} 3, \mathrm{a}}$ and $\mathrm{W}_{\mathrm{s} 3, \mathrm{~d}}$ are the respective third period wealth levels of the child, that he or she uses in bargaining with the grandchild, contingent upon the parent being alive or dead in period 4. Problem (18) involves maximizing a weighted sum of the two participants' expected utility where the weight $\theta$, applied to the child's utility, potentially ranges from 0 to $\infty$. The child considers his or her consumption in periods 3 and 4 under two eventualities: either the parent dies early, and the child does not have to pay off on the annuity insurance agreement (this is refiected in the final term of (18) which is weighted by the (1-P) possibility of 1ts occurrence), or the parent dies late and, hence, the child does have to pay off on the annuity insurance (the fourth term in (18)). As stated, the $\hat{v}(w)$ function gives the expected utility the child experiences from his third and fourth period consumption discounted to period 3 of his life as a function of his wealth in period 3 . Problem (18) has two budget constraints; total consumption plus savings for the child's third period equals total initial wealth of the parent and child under both lifetime possibilities for the parent. The weight $\theta$ 
reflects the terms of trade in this bargaining problem. In general one would expect $\theta$ to be a function of the resources of both the parent and the child, $W_{f 3}$ and $W_{s 1}$, respectively. However, since $W_{s 1}$ is constant in our analysis, we express $\theta=\theta\left(w_{f 3}\right)$.

Solving problem (18) for different values of $\theta$ traces out the utility possibility frontier for family deals shown in Figure 1. Obviously, not all values of $\theta$ will generate outcomes that are in the core. We have labeled as $\theta_{s}$ the critical value for $\theta$ for which the parent receives none of the gains from trade (i.e., the child receives all gains from trade). $\theta_{f}$ is defined symmetrically with the parent getting all of the surplus. The point $T$ is the threat point, indicating the parent's and child's expected utility levels if they fail to bargain with each other. As is clear from problem (18), figure 1 depends on the respective resources of the father and the son, $w_{s l}$ and $w_{f 3}$, and on the function $\hat{v}_{s}(\cdot)$.

Since we consider a stationary environment in which tastes and endowments of children remain unchanged, we will limit outself to stationary bargaining solutions. That is, we assume that the $\hat{v}$ function will be the same for the bargaining of each successive pair of generations. An implication of stationarity is that the parent's expected utility in (18) expressed as a function of his wealth, $W_{\mathrm{f3}}$, equals the child's expected utility function, $\hat{v}$, when the child becomes a father. An immediate property of stationarity is that the child reaches the same deal with his child as his parent did with him if respective resources are the same. More formally, a stationary solution is defined as a bargaining function $\theta\left(w_{f 3}\right)$ and an expected utility function $V(W)$ such that if $C_{f 3}^{*}, C_{f 4}^{*}$ are optimal 


\section{Figure 1. Utility Possiblililes Frontier}

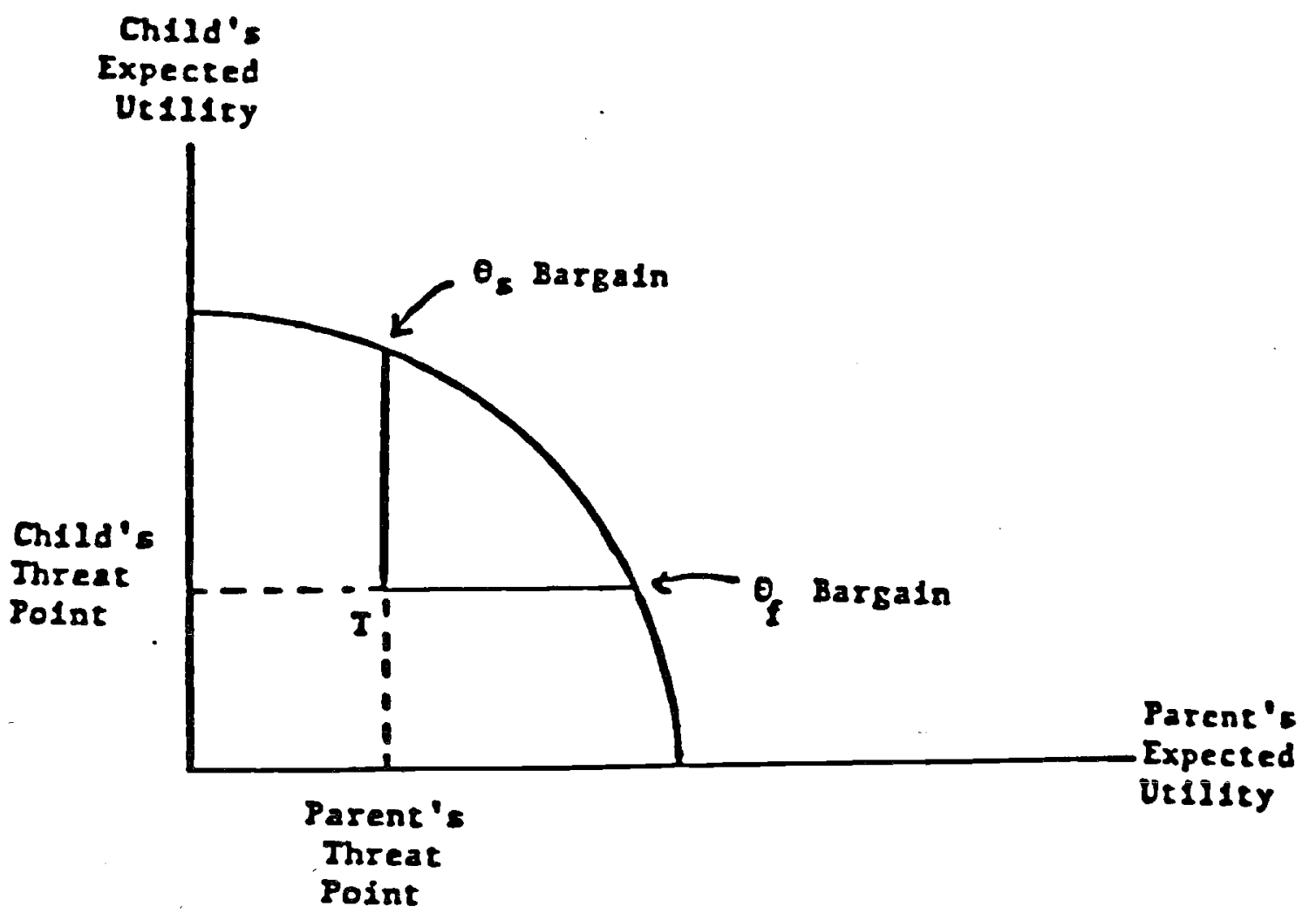


values of consumption derived from solving problem (18), where

$v\left(w_{s 3}\right)$ is substituted for $\hat{v}\left(w_{s 3}\right)$, then $v\left(w_{f 3}\right)=\frac{1}{1-\gamma} c_{f 3}^{1-\gamma}+\alpha P_{1-\gamma} c_{f 4}^{1-\gamma}$.

Solving problem (18) involves searching for a fixed point

function $V$ and an associated $\theta\left(w_{f 3}\right)$ function that produces outcomes that are in the core. We consider and compute three solutions to problem (18). In the first solution, denoted $\theta_{s}$, the child receives all the gains from trade; furthermore, all successive bargains involve children receiving all gains from trade. In the second, $\theta_{f}$ solution, the initial and all successive fathers receive all gains from trade. In the third solution the gains from trade are always divided between child and son according to John Nash's (1954) two person bargaining solution.

In the $\theta_{s}$ solution parents receive their threat point level of expected utility. This is the expected utility received by the parent if he acts on his own and is given by the solution to (21). Maximize:

$$
\frac{C_{f 3}^{1-\gamma}}{1-\gamma}+\frac{\alpha P C_{f 4}^{1-\gamma}}{1-\gamma}
$$

subject to

$$
C_{f 3}+R C_{f 4}=W_{f 3}
$$

Denote $v_{8}\left(w_{f 3}\right)$ as the maximum utility that the parent with wealth $W_{f 3}$ can achieve on his own by solving $(21) . v_{s}\left(w_{f 3}\right)$ is, thus, the indirect utility function when no deal is struck and is given by:

$$
v_{s}\left(w_{f 3}\right)=\frac{w_{f 3}^{1-\gamma}}{1-\gamma}
$$

where 


$$
k=R^{\gamma-1}\left(\left(1+(\alpha P)^{1 / \gamma_{R}} \frac{\left(\frac{\gamma-1}{\gamma}\right)}{\gamma}\right)^{\gamma}\right.
$$

Naturally, $v_{s}\left(w_{f 3}\right)$ is the minimum the parent is willing to accept in an annuity bargain with his child. $v_{s}$ is also the expected utility function of the child in the $\theta_{s}$ bargain with his own child. Replacing $\hat{v}_{*}$ ith $v_{s}$ in $(18)$ and choosing $\theta_{s}$ for each value of $w_{f 3}$ such that $v_{s}\left(w_{f 3}\right)=\frac{C_{f 3}^{* 1-\gamma}}{1-\gamma}+\alpha \frac{P_{f 4}^{*} 1-\gamma}{1-\gamma}$ provides a proof by construction that $v_{s}$ is a fixed point function for the $\theta_{s}$ problem. In addition the computed values of $\theta_{s}$ for different values of $w_{f 3}$ determine the function $\theta_{s}\left(w_{f 3}\right)$. While parents, in this $\theta_{s}$ bargain, receive their threat point levels of expected utility, their actual pattern of consumption differs from what they would choose on their own;

$C_{f 3}^{*}$ is smaller and $C_{f 4}^{*}$ greater than the respective solution values to problem (21).

Although the $\mathrm{V}_{\mathrm{s}}$ function was obtained analytically, finding an analytic expression for $\hat{V}$ for other bergaining solutions is generally not possible. For the the $\theta_{f}$ and Nash (denoted $\theta_{n}$ ) solutions an iterative technique described below is used to find fixed point functions and their associated $\theta$ functions. Both the $\theta_{f}$ and $\theta_{n}$ solutions require specifying the child's threat point. Given our assumption of a cooperative, efficient solution to parent/child bargaining, the child, if he (she) fails to bargain with the parent, can credibly assert to the parent that he (she) will be able to reach a deal with his child. The child's threat point $\mathrm{EU}_{\mathrm{s}}^{\mathrm{T}}$, is the solution to problem (22); it involves the child's consuming $C_{s 1}$ and $C_{s 2}$ in his first two periods, respectively, and bargaining with his child in period 3 based on third period wealth, $w_{s 3}$. 
Maximize:

$$
\mathrm{EU}_{s}^{\mathrm{T}}=\frac{C_{s I}^{1-\gamma}}{1-\gamma}+\frac{\alpha C_{s 2}^{1-\gamma}}{1-\gamma}+\alpha^{2} \hat{v}\left(w_{s 3}\right)
$$

subject to

$$
C_{s 1}+R C_{s 2}+R W_{s 3}=W_{s 1}
$$

In the case of $\hat{\theta}_{f}$ bargaining, $\hat{v}$ is replaced by $v_{f}$ in (22) as well as (18). The $\theta_{f}$ solution proceeds by first guessing a function $v_{f} \cdot$ Next we solve (22) to determine the son's threat point utility $\mathrm{EU}_{\mathrm{s}}^{\mathrm{T}}$. Given the guess of $\mathrm{V}_{f}$ and the derived value of $\mathrm{EU}_{\mathbf{s}}^{\mathrm{T}}, \theta$ is choosen in (18) such that the son's expected utility in the solution to (18) equals $\mathrm{EU}_{\mathrm{s}}^{\mathrm{T}}$. This last calculation is repeated for different values of $W_{f 3}$ thereby generating a function $\theta_{f}\left(w_{f 3}\right)$. In addition to computing a $\theta_{f}$ function based on the initial guess of $v_{f}$, the solution to (18) based on $\theta_{f}\left(W_{f 3}\right)$ determines the father's expected utility in the bargain. The maximizing values of $\frac{C_{f 3}^{* 1-\gamma}}{1-\gamma}+P \alpha \frac{C_{f 4}^{* 1-\gamma}}{1-\gamma}$ for different values of $W_{f 3}$ provide an expected utility function for the parent in the $\theta_{f}$ bargain with the child. This function is used as the next guess of the $v_{f}$ function, and the calculations are repeated. The iteration proceeds until the guess of the $v_{f}$ function equals the parent's expected utility as a function of $W_{f 3}$, i.e., until we have found a function $V_{f}$, which is a fixed point of the mapping described.

In the Nash bargaining case a very similar solution technique is applied. The Nash solution involves choosing $\theta$ in (18) to maximize the quantity $\left(E U_{f}-E U_{f}^{T}\right)\left(E U_{s}-E U_{s}^{T}\right)$, where $E U_{f}$ and $E U_{s}$ are the expected utilities obtained by the parent and child respectively, and $\mathrm{EU}_{\mathrm{f}}^{\mathrm{T}}$ equals 
$\mathrm{V}_{s}$, the parent's threat point. To find $\mathrm{V}_{n}$, the Nash fixed point function, we again choose an initial guess of $V_{n}$ and solve (22) to find $\mathrm{EU}_{\mathrm{s}}^{\mathrm{T}}$. We also solve (2I) to find $\mathrm{EU}_{\mathrm{f}}^{\mathrm{T}}$. Next the guessed value of $\mathrm{V}_{\mathrm{n}}$ is substituted for $\hat{V}$ in (18), and $\theta_{n}$ is choosen to maximize $\left(E U_{f}-E U_{t}^{T}\right)\left(E U_{s}-E_{s}^{T}\right)$. Repeating this last step for alternative values of $W_{f 3}$ generates a function $\theta_{n}\left(w_{f 3}\right)$ as well as an expected utility function of the father arising from Nash bargaining. This latter function is used as the second guess of the $v_{n}$ function. The iteration continues until we find a fixed point function $V_{n}$. In this bargaining solution as in the previous $\theta_{s}$ solution, the $\theta_{f}\left(w_{f 3}\right)$ and $\theta_{n}\left(w_{f 3}\right)$ functions calculated in the last round of the iteration correspond to the correct bargaining functions for the functions $V_{f}$ and $v_{n}$, respectively.

The $V_{s}$ function is used as the initial guess of the $V$ function for the $\theta_{f}$ and Nash bargaining solutions. In each iteration we computed the solution to (18) for 80 different values of $\mathrm{w}_{\mathrm{f}}$. We then fit a fifth order polynominal in $w_{f 3}$ to these points and used the resulting regression as the guess of $\mathrm{V}$ in the next iteration. The iterative procedure for determining $\mathrm{V}$ converged roughly by the 8 th iteration; ${ }^{8} 12$ iterations each were used for both the $\theta_{f}$ and Nash cases.

\section{Savings in the Life Cycle Model under Imperfect Family and Perfect}

\section{Insurance Arrangements}

As described more fully in Kotlikoff, Shoven, and Spivak (1983), the stochastic steady state of the life cycle economy has a stationary and bounded savings distribution. The distributions and stocks of wealth for each of the bargaining cases were computed numerically as follows: first, we calculated 
the function $w_{s 3, a}^{a}\left(w_{f 3}\right)$ and $w_{s 3, d}^{a}\left(w_{f 3}\right)$ for each of the three solutions to problem (18). These two functions indicate the third period wealth of a child (when the child becomes a parent) whose parent brings $w_{f 3}$ to the bargain and who dies, resprectively, either early or late. Starting with one hundred thousand families with the same initial value of $w_{f 3}$, we randomiy assigned these two functions to each family in each generation according to the probability $P$ of survival to period 4. The distribution of $W_{f 3}$ stabilized after roughly 8 generations. Unlike the case of unconstrained altruistic economies, there is a non-zero positive lower bound as well as an upper bound on family resources.9 The degree of inequality in parental asset holdings $\left(W_{f 3}\right)$ generated by this model is rather moderate. The upper bound for $\mathrm{W}_{\mathrm{f} 3}$ is only 1.7 times the lower bound for our base line parameters under $\theta$ bargaining. The poorest 50 percent of parents have close to 45 percent of all parental assets, and the richest 10 percent have 18 percent of all assets. These figures proved highly robust to a wide range of parameter values.

Table III compares steady state per capita wealth stocks in the different insurance regimes under alternative assumptions about age earnings profiles.10 Each of the age earnings profiles has a present value of 10 , which is received with certainty over the course of the first three periods. Since the child's resources are identical in each of these cases, the consumption decisions of the child and parent are the same for each of these earnings paths. Hence, the difference in stocks of wealth by row in Table III are simply a function of the timing of the recelpt of labor income. The earnings profile in the third row appears closest to the shape of real world profiles. 


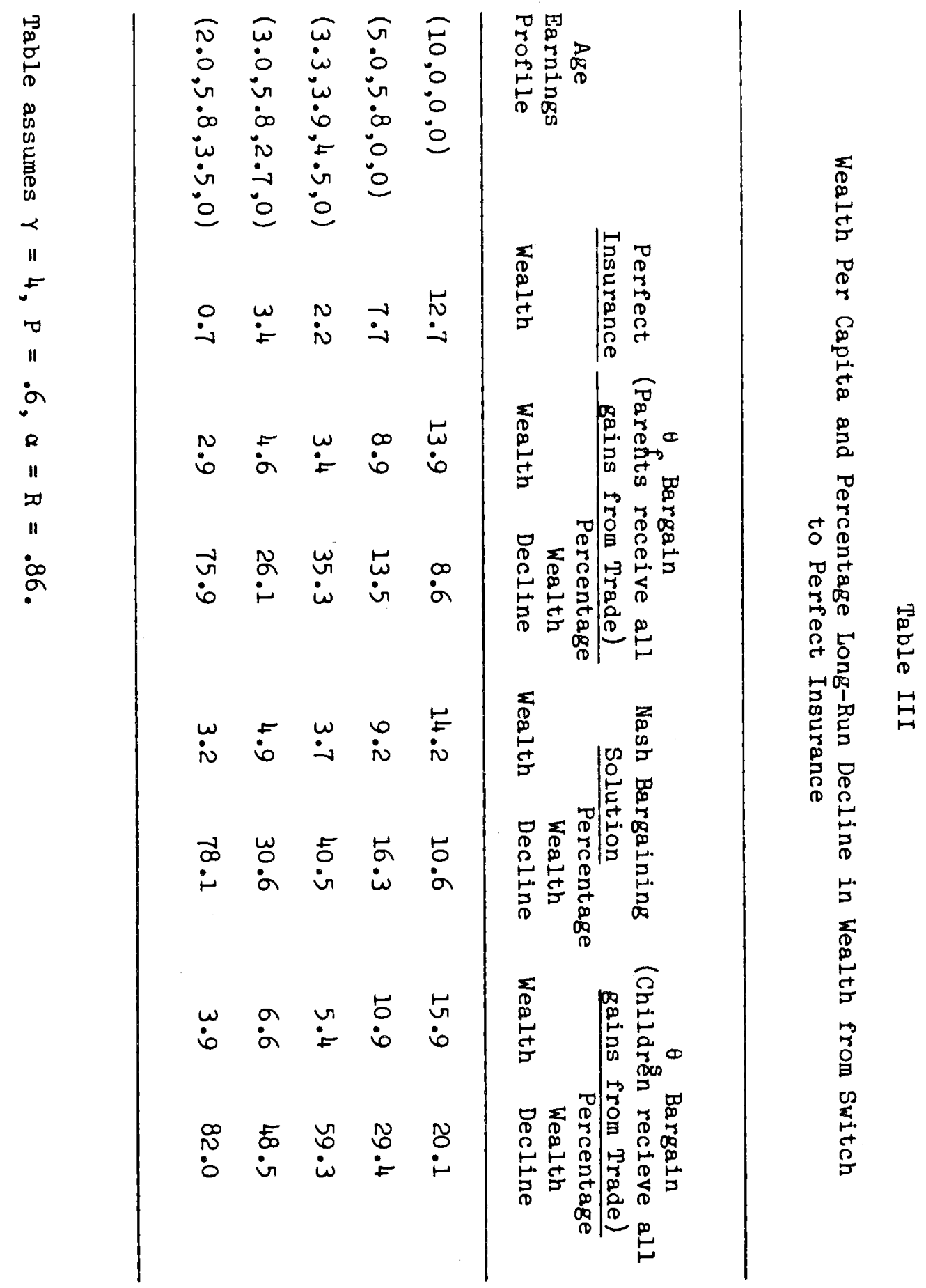


The percentage reductions in wealth from moving to perfect insurance reported in Table IV are very large. For the earnings profile in the third row the long-run wealth reduction is 59 percent starting from the $\theta_{8}$ (children take all) stochastic steady state. It is 41 percent in the case of an initial Nash bargaining equilibrium and 35 percent when the initial equilibrium involves $\theta_{f}$ (parents take all) bargain.

In contrast to the altruistic models of sections II and III, a mor factor explaining the savings reduction in this model is the implicit intergenerational transfer associated with providing perfect annuity insurance. In the family insurance equilibrium the expected inheritance of children is positive since children would not otherwise be wllling to accept the additional consumption risk arising from the parent-child annuity arrangement. Once perfect insurance is available, parents as a collective group, will consume what they would otherwise have bequeathed, on average, to their children. This negative resource transfer from younger children to older parents reduces the economy's savings because the parents, with shorter life spans, have higher marginal consumption propensities than have their children. This intergenerational transfer explains why savings falls significantly in the life cycle model from introducing perfect insurance regardless of the value of $Y$. Recall that in the altruistic model of section II, introducing perfect insurance lowers savings only very slightly for $\gamma<1$. The values in Table III are highly sensitive to the shape of the age earnings profile. The smallest percentage wealth reduction arises when all earnings are recelved in the first period; in this case wealth falls by 
20.1 percent starting from the $\theta_{s}$ bargain and by 13.9 percent starting from the $\theta_{f}$ bargain.

The percentage change in wealth appears relatively insensitive to variations in the degree of relative risk aversion, $\gamma$. For example, reducing $Y$ from 4 to 1.5 lowers the percentage decline in wealth under row 3 's earnings profile and initial $\theta$ bargaining from 59.3 percent to 50.7 percent. Raising $\gamma$ to 8 increases the value to 63.2 percent. Under Table III's first age earnings profile the percentage wealth reductions starting from $\theta_{s}$ economies are $15.1,20.1$, and 22.9 for values of $\gamma$ equal to $1.5,4$, and 8 , respectively.

There is considerably more sensitivity to changes in the fourth period survival probability P; however, the sensitivity depends on the choice of earnings profile. For example, lowering P from .6 to .3 , which reduces the expected age of death from roughly 74 to roughly 69 , converts the 59.3 percent $\theta_{s}$ reduction (row 3, Table III) to 83.6 percent. The same reduction in $P$ raises Table III's row $1, \theta_{s}$ value from 20.1 percent to only 23.4 percent.

Unlike the previous two sections the analysis here is partial equilibrium, 1.e., the wage and interest rate are assumed fixed. Since the wealth reduction from introducing fair annuity insurance would increase rates of return and depress wages which stimulates savings, the general equilibrium differences between family and perfect insurance are likely to be considerably smaller than these partial equilibrium differences.

The large differences in wealth stocks in partial equilibrium bet- 
ween the perfect insurance and family insurance regimes suggests that steady state welfare could actually be lower in the case of perfect insurance. This is indeed possible. Under $\theta_{f}$ (children take all) bargaining and assuming $\gamma$ equals 1.5 , the expected utility of even the child of the poorest parent exceeds the uniform, steady state expected utility under perfect insurance. Starting from a situation of zero insurance, achieving the perfect insurance expected utility level requires a 7 percent increase in resources; achieving the expected utility of the child with the poorest parent in the $\theta_{s}$ stochasic steady state requires an 8 percent increase in life-time resources, starting from this benchmark regime. Attaining the level of welfare of the child whose parent in the $\theta_{f}$ steady state has the maximum potential wealth requires a corresponding 12 percent increase in resources.

Another question raised by Table III is the extent to which imperfections in annuity markets can fully explain observed intergenerational transfers. Kotlikoff and Summers (1981) invoked the assumption of perfect insurance arrangements in estimating that roughly 80 percent of private U.S. wealth corresponds to accumulated inheritances of those currently alive. This assumption that annuity insurance is fairly well developed in the United States can be defended by pointing to social security and other government annuities, private pensions, old age labor earnings that are partly contingent on survival, and the potential for family risk sharing involving multiple members. St1ll, it is interesting to ask how their calculation turns out when it is applied to the two member family insurance econom described above. Their technique involves subtracting accumulated 
consumption from accumulated earnings for each cohort and then sumning across cohorts to get a total wealth stock. Th1s "life cycle" wealth is then compared with actual wealth holdings. If agents in the economy are selfish and annuity arrangements are perfect or very close to perfect, computed and actual aggregate wealth will be identical or extremely close to one another.

The two person family regime is, however, quite far from that of perfect insurance. As described here, this imperfection produces a stochastic steady state in which observed consumption profiles often exceed what could be financed from one's own labor earnings even under perfect insurance. Hence, in this economy, subtracting, for all cohorts, accumulated consumption, part of which is financed by past intergenerational transfers, from accumulated earnings produces an underestimate of the economy' actual wealth. For the $\theta_{s}$ bargain, with $\gamma$ equals 4 and with Table III's row 3 earnings profile, the underestimate is close to 90 percent of actual wealth. Since Kotlikoff and Summers' calculation understates U.S. wealth by 80 percent, imperfections in annuity markets appear potentially capable of fully explaining actual U.S. intergenerational transfers. 
V. Summary and Conclusions

This paper has explored the impact of perfecting annuity insurance on savings and inequality using two standard neoclassical models -- the intergenerationally altruistic model and the non-altruistic life cycle model. While the modeling is intentionally structured to produce the maximum precautionary savings, the results are, nonetheless, quite surprising. Partial equilibrium calculations based on the life cycle model suggest very substantial reductions in national wealth associated with improving annuity insurance. Indeed, in the life cycle model the reduction in savings from the annuity insurance associated with social security could be larger than the savings reduction arising from social security's "pay as you go" method of finance. In addition, imperfections in annuity insurance appear potentially capable of explaining a sizeable fraction of observed intergenerational transfers in the U.S..

In the intergenerationally altruistic model perfecting annuity insurance can also significantly lower national savings, but the results here are much more sensitive to precise parameter values as well as assumptions about liquidity constraints.

In the presence of family annuity insurance each of the models provides a theory of the distribution of resources. While the life cycle model suggests a rather limited dispersion in family resources in the stochastic steady state, the altruistic model, absent liquidity constraints, generates increasing inequality through time. Assymptotically the altruistic model's resource distribution is completely skewed. In the long run virtually all 
families hold close to zero resources and an infinitesimal fraction of families hold all of the economy's wealth. The results of this analysis suggest the importance of studying other motives for precautionary savings such as uncertainty with respect to future earnings and future health status. A variety of government programs, including disability and unemployment insurance, welfare, and progressive taxation my be greatly affecting the extent of precautionary savings in the economy. To the extent that such savings is highly responsive to government insurance programs, the government may wish to offset their adverse savings effects not by reducing its provision of insurance, but by using alternative policy instruments that raise savings without increasing economlc uncertainty. 


\section{Footnotes}

1. Our discussion of behavior in the life cycle model draws heavily on Kotlikoff, Shoven, and Spivak (1983).

2. See Kotlikoff and Spivak (1981). This statement assumes independent morality probabilities across family members.

3. The formula for $g()$ is:

$g(P, \alpha, \theta, R, \gamma, k)=$

$\left[a^{1 / \gamma}+\alpha^{1 / \gamma_{R} \frac{\gamma-1}{\gamma}}\left[P\left(a+\alpha^{1 \gamma} R^{\frac{\gamma-1}{\gamma}} k^{1 / \gamma}\right)^{\gamma}+(1-P)\left(\theta^{1 / \gamma}+a^{1 / \gamma}{ }_{R}^{\frac{\gamma-1}{\gamma}} k^{1 / \gamma}\right)^{\gamma}\right]^{\gamma}\right]^{1 / \gamma}$,

where $a=\left(1+\theta^{1 / \gamma}\right)^{\gamma}$. For each set of particular values considered

in the paper there is a unique value $k$ satisfying $k=g()$.

4. A and $D$ are given by:

$$
\begin{aligned}
& A=R^{2}\left(1-(M / a)^{-1 / \gamma}\right)\left(1-(k / a)^{-1 / \gamma}\right) \\
& D=R^{2}\left(a-(N / \theta)^{-1 / \gamma}\right)\left(1-(k / a)^{-1 / \gamma}\right)
\end{aligned}
$$

where

$$
\begin{aligned}
& a=\left(1+\theta^{1 / \gamma}\right)^{\gamma}, M=\left[a^{1 / \gamma}+\left(\alpha R^{-1} \nu\right)^{1 / \gamma} R\right]^{\gamma} \text {, and } \\
& \left.N=\left[\theta^{1 / \gamma}+\left(\alpha R^{-1} \nu\right)^{1 / \gamma}\right)^{1 / \gamma} R\right]^{\gamma} \text {. }
\end{aligned}
$$

5. Actually Chebyshev's theorem provides an even stronger statement about changes in the distribution of family resources through time. Let $c$ be an arbitrary constant. Then the probability at time t that $\log _{t+\tau}$ exceeds $c$ is bounded by a number that declines with $\tau$ if $\operatorname{logh}_{t}$ is less than or equal to $c$. 
If $\log w_{t}$ exceeds $c$, the bound on the probability that $\log w_{t+\tau}$ exceeds $c$ declines with $\tau$ for $\tau>\frac{\log W_{t}-c}{\gamma}$. In other words the bound of $P\left(\log w_{t+\tau}>c\right)$ monotonically declines with $\tau$ if the process has already reached $c$; and if not, it declines monotonically once the process has had enough time to drift down to $c$. More formally, from Chebyshev's theorem we have:

$$
P\left(\log W_{t+\tau}>\log W_{t}-\tau \rho+\lambda \sqrt{\tau} \sigma\right)<1 / \lambda^{2},
$$

where $\lambda$ is a positive constant. Choose $\tau$ such that $c=\log W_{t}-\tau \rho+\lambda \sqrt{\tau \sigma}$, then:

$$
\begin{aligned}
& P\left(\log W_{t+\tau}>c\right)<1 / \lambda^{2} \text {, where } \lambda=\frac{c-\log W_{t}+\tau \rho}{\sqrt{\tau \sigma}} . \\
& \text { Since } \tau \rho>\log W_{t}-c, \frac{\partial \lambda}{\partial \tau}>0 \text { and } \frac{\partial\left(1 / \lambda^{2}\right)}{\partial \tau}<0 .
\end{aligned}
$$

6. The intuitive explanation here is that as the time preference factor approaches unity families become increasingly indifferent between their own welfare and that of their far distant, indeed infinitely distant descendents. At the limit, when a equals 1, current family members are completely indifferent between consuming now and saving everything for the future consumption of their descendents. They are also indifferent with respect to allocating consumption at any point in time between children and parents, i.e., eliminating parental consumption and thereby the entire concern with life span uncertainty, is a matter of indifference to families when a equals 1. Since Iffespan uncertainty becomes an increasingly less important issue as a rises, it is not surprising that for a equal to .99 , savings with imperfect insurance is equal to savings with perfect insurance. 
7. By "rough convergence" we mean that economic choice variables were identical to at least the second digit between iterations. For a range of intermediate values of $\mathrm{W}_{\mathrm{f} 3}$ the calculated consumption terms are identical to five digits between iterations. While we believe more accurate values of the $v_{s}$ and $v_{n}$ functions could be obtained, the computation costs of achieving the additional accuracy is considerable; solving (18) for any one of the 80 values of $w_{f 3}$ in any one of the 12 iterations requires rather extensive computation.

8. The explanation for the upperbound is the following: As successive parents continue to die early their children bring more, but not proportionately more resources into their own third period. When the parent dies early, his or her child enjoys an increase in non-human wealth, but no change in human wealth. Hence, when the child's non-human wealth rises by a given percentage, his or her total wealth rises by a smaller percentage. Hence, even if a two period old child increased his (her) $w_{f 3}$ proportionately in response to an increase in total resources available at the beginning of period 2, the increased non-human wealth received in period 2 would lead to a less than proportional increase in $\mathrm{w}_{\mathrm{f3}}$.

9. The absolute size of these economies' wealth stocks may appear small in comparison to the level of earnings or income in a particular period. However, such stock-flow ratios mist be adjusted for the fact that flows in this model are recelved over a period that corresponds to roughly 15 years. In the case of the third and probably the most realistic earnings profile in 


$$
-38-
$$

Table IV, the ratio of wealth to one-fifteenth of a period's labor earnings is 6.9 in the case of the $\theta_{\mathrm{s}}$ bargain. A wealth-to-earnings ratio of 6.9 is somewhat greater than that observed in the United States. 


\section{References}

Abel, Andrew B., Bequests with Uncertain Lifetimes, mimeo, April 1983.

Barro, Robert J., "Are Government Bonds Net Wealth?" Journal of Political Economy, Vol. 82, November-December 1974, pp. 1095-118.

Davies, J.B., "Uncertain Lifetime Consumption and Dissaving in Retirement," Journal of Political Economy, Vol. 89, June 1981, pp. 561-78.

Denardo, E., "Contraction Mappings in the Theory Underlying Dynamic Programming," SIAM Review, Vol. 9, 1967, pp. 165-77.

Eckstein, Zvi, Martin S. Eichenbaum, and Dan Peled, The Distribution of Wealth and Welfare in the Presence of Incomplete Annuity Markets," mimeo, May 1983.

Feldstein, Martin S., "Social Security, Induced Retirement and Aggregate Capital Accumlation," Journal of Political Economy, Vol. 82, October 1974, pp. 905-26.

Hausman, Jerry, "Individual Discount Rates and Utilization of Energy Using Durables," Bell Journal, Spring 1979, pp. 33-54.

Hubbard, Glenn R., Uncertain Lifetimes and the Impact of Social Security on Individual Wealth Accumulation, mimeo, May 1983.

Kotlikoff, Laurence J. and Avia Spivak, "The Family as an Incomplete Annuities Market," Journal of Political Economy, Vol. 89, April 1981, pp. 372-91.

Market," NBER Working Paper, 1980'

, "The Family as an Incomplete Annuities

Kotlikoff, Laurence J. and Lawrence H. Summers, "The Role of Intergenerational Transfers in Aggregate Capital Accumulation," Journal of Political

Economy, Vol. 90, August 1981, pp. 706-32.

Kotlikoff, Laurence J., John B. Shoven, and Avia Spivak, "Annuity Markets, Savings, and the Capital Stock," NBER Working Paper No. 1250, December 1983.

Sheshinsk1, E. and Y. Weiss, "Uncertainty and Optimal Social Security Systems," Quarterly Journal of Economics (1981), pp. 189-206.

Stiglitz, Joseph, "Intergenerational Transfers and Inequality," with D. Bevan, The Greek Economic Review, Vol. 1, No. 1, August 1979, pp. 8-26, (paper presented at AEA Meetings, Chicago, 1978).

, "Equality, Taxation and Inheritance," in Personal Income Distribution, edited by W. Krelle and A.F. Shorrocks, North-Holland 
$-40-$

Publishing Company, 1978, pp. 271-303, (proceedings of IEA Conference, Noordwifk an Zee, Netherlands, April 1977.

Yaari, M.E., "Uncertain Lifetime, Life Insurance, and the Theory of the Consumer," Review of Economic Studies, Vol. 32 (1965), pp. 137-50. 